\title{
Downregulation of Rap1 promotes 5-fluorouracil-induced apoptosis in hepatocellular carcinoma cell line HepG2
}

\author{
YONG ZHA $^{1 *}$, PING GAN $^{1 *}$, QIAN YAO ${ }^{2}$, FENG-MING RAN $^{3}$ and JING TAN ${ }^{1}$ \\ ${ }^{1}$ Department of Abdominal Surgery, ${ }^{2}$ Yunnan Cancer Research Institute, ${ }^{3}$ Department of Pathology, \\ Yunnan Cancer Hospital (The Third Affiliated Hospital, Kunming Medical University), Kunming, Yunnan 650118, P.R. China
}

Received December 9, 2013; Accepted January 30, 2014

DOI: $10.3892 /$ or.2014.3033

\begin{abstract}
Recent studies have revealed that repressor/activator protein (Rap1) not only protects telomeres from sister chromatid exchange, but also functions in genomewide transcriptional regulation. Knockdown of Rap1 sensitizes breast cancer cells to adriamycin-induced apoptosis. However, little is known about the role of Rap1 in the progression of hepatocellular carcinoma (HCC). The present study aimed to investigate the functions of Rap1 in HCC progression and to determine whether targeting the Rap1 signaling pathway may be of therapeutic value against HCC. We found knockdown of Rap1 by microRNA (miRNA) interference enhanced significantly apoptosis and 5-fluorouracil (5-FU) chemosensitivity in HepG2 cell line. Rap1 miRNA downregulated nuclear factor $-\kappa \mathrm{B}$ p65 (NF- $\kappa \mathrm{B}$ p65) expression, and upregulated inhibitor of $\mathrm{NF}-\kappa \mathrm{B}(\mathrm{I} \kappa \mathrm{B})$ expression. In vivo, Rap1 miRNA combined with 5-FU treatment led to a significant reduction of tumor growth as compared with 5-FU alone. The results indicate that Rap1 miRNA can effectively enhance sensitivity of HepG2 cell line to 5-FU chemotherapy in vitro and in vivo.
\end{abstract}

\section{Introduction}

Hepatocellular carcinoma (HCC) is the the fifth most common cancer and the third leading cause of cancer-related death in the world (1). Its annual incidence is estimated at 600,000 new cases, more than half of which come from China (2). Surgical resection is the most effective therapy for HCC. However, most of the patients are not good candidates for surgery because of being diagnosed in later stages. On the other hand, HCC is frequently resistant to conventional chemotherapeutic agent-

Correspondence to: Dr Yong Zha, Department of Abdominal Surgery, Yunnan Cancer Hospital (The Third Affiliated Hospital, Kunming Medical University), No. 519 Kunzhou Road, Kunming, Yunnan 650118, P.R. China

E-mail: zhayong888@sina.com

*Contributed equally

Key words: Rap1, hepatocellular carcinoma, NF-кB, apoptosis sand radiation (3). Resistance to apoptosis is one of the reasons that HCC cells are not sensitive to chemotherapy $(4,5)$.

Some studies have revealed that NF- $\kappa \mathrm{B}$ is constitutively activated and plays a vital role in the regulation of genes involved in cell apoptosis in some cancers including HCC $(6,7)$. Inhibition of NF- $\mathrm{B}$ p65 by miRNA resulted in a significant increased apoptosis in HCC (8). Interestingly, Rap1 (repressor/activator protein), a member of telomeres shelterin complex, has been shown to be an essential modulator of $\mathrm{NF}-\kappa \mathrm{B}-$ mediated pathways (9). Human breast cancers with $\mathrm{NF}-\kappa \mathrm{B}$ hyperactivity show elevated levels of cytoplasmic Rap1. Knockdown of Rap1 sensitizes breast cancer cells to apoptosis (9). However, to date, few studies have reported the biologic function of Rap1 in HCC progression, the interactive regulation between Rap1 and $N F-\kappa B$, and the potential functional contribution of such a network to HCC cancer progression and apoptosis have not been explored yet.

In the present study, to investigate the role of Rap1 in HCC progression, we examined cell survival/growth and apoptosis after downregulation of Rap1 expression by miRNA in HepG2 cells, and explored its mechanisms.

\section{Materials and methods}

Cell culture. HepG2, HuH-7, SMMC-7721, QGY-7703 and HL-7702 cell lines were obtained from Shanghai Cell Bank. The cells were maintained under a humidified atmosphere of $5 \% \mathrm{CO}_{2}$ at $37^{\circ} \mathrm{C}$ in DMEM medium (HyClone), supplemented with $10 \%$ fetal bovine serum (FBS; HyClone).

Transient transfection of HepG2 cells and establishment of stable transfectants. Set of four Rap1-miRNA oligonucleotides were designed and synthesized by Invitrogen for Rap1 gene knockdown studies. The Rap1-miRNA expression vector (pcDNATM 6.2-GW/EmGPF-miR; Invitrogen; catalog no. K4936-00) was used to construct a Rap1 miRNA plasmid by inserting the miRNA-coding sequence. HepG2 cells were transfected with selected Rap1-miRNA plasmid or control miRNA plasmid.

HepG2 cells were seeded on 6-well plates at a density of $5 \times 10^{5}$ cells/well, and grown for 48 h to reach $80 \%$ confluence before transfection. Control miRNA and Rap1 miRNA were transfected respectively into cells using Lipofectamine 2000 (Invitrogen; catalog no. 11668-027) according to the manufac- 
turer's instructions. The cells were then harvested and analyzed by flow cytometry, electron microscopy, reverse transcriptase polymerase chain reaction (RT-PCR) and western blot analysis at 24-72 $\mathrm{h}$ after the transfection. All measurements were performed in triplicate.

The transfected cells were cultured in the medium with Blasticidin S HCl (Invitrogen; catalog no. R210-01) at $2-10 \mu \mathrm{g} / \mathrm{ml}$. After 8 weeks, surviving colonies arising from stably transfected cells were selected and individually amplified.

MTT assay. At $48 \mathrm{~h}$ after transfection, cell survival was measured by the 3-(4,5-dimethylthiazol-2-yl)-2,5-diphenyltetrazolium bromide (MTT) assay. The transfected and control cells were seeded at a density of 5,000 cells/well in 96-well plates and incubated at $37^{\circ} \mathrm{C}$ in humidified $5 \% \mathrm{CO}_{2}$ for $24 \mathrm{~h}$. Serially diluted 5-FU (Sigma) was added to give the intended final concentrations. Cells were then incubated an additional $72 \mathrm{~h}$, and the MTT assay was performed according to the manufacturer's instructions. Absorbance values were determined at $570 \mathrm{~nm}$ on a SpectraMax 250 spectrophotometer. The assays were performed three times in triplicate. The 50\% inhibitory concentration $\left(\mathrm{IC}_{50}\right)$ values were defined as the drug concentrations required to reduce cellular proliferation to $50 \%$ of the untreated control well.

Flow cytometry for apoptosis. The HepG2 cells were harvested for evaluation of apoptosis at 48 and $72 \mathrm{~h}$ after the transfection. Firstly, the cells were washed with PBS and fixed in $4 \%$ paraformaldehyde for $30 \mathrm{~min}$. Then, the cells were re-suspended in PBS supplemented with $0.1 \%$ Triton $\mathrm{X}-100$, and incubated at $4^{\circ} \mathrm{C}$ for $2 \mathrm{~min}$. TUNEL solution $(50 \mu \mathrm{l})$ was added to each tube, and incubated in the dark at $37^{\circ} \mathrm{C}$ for $60 \mathrm{~min}$. After that, the cells were washed with PBS, and re-suspended in $250 \mu \mathrm{l}$ PBS for flow cytometry using the FACSCalibur system.

Electron microscopy. The cells were harvested in PBS for evaluation of apoptosis with electron microscopy at $48 \mathrm{~h}$ after the transfection. Firstly, the cells were subsequently fixed in $3.5 \%$ glutaraldehyde and $1 \% \mathrm{OsO}_{4}$, then, washed with $\mathrm{PBS}$, dehydrated in ethanol and acetone series, and embedded in Epon 618. Thin sections were cut with a Leica Ultracut UCT microtome, stained with $2 \%$ uranyl acetate and lead citrate. Observation followed using JEM-1011 transmission electron microscopy.

Quantitative real-time PCR. To elucidate the mechanism by which Rap1 induces cell growth and inhibits apoptosis in $\mathrm{HCC}$, we examined the expression of NF- $\mathrm{KB}$ p 65 and $\mathrm{I} \kappa \mathrm{B}$ using quantitative real-time PCR at $48 \mathrm{~h}$ after the transfection. Total RNA was isolated from the Rap1 miRNA transfected and control cell lines with TRIzol (Invitrogen; catalog no. 15596-026). Then, the RNA was subjected to real-time PCR analysis with the use of a One Step SYBR PrimeScript RT-PCR kit (Bio-Rad Laboratories) and superscript preamplification system (Invitrogen Life Technologies). NF- $\kappa \mathrm{B}$ p65 was amplified using forward primer 5'-GGGAAGGAACG CTGTCAGAG-3' and reverse primer 5'-TAGCCTCAGGG TACTCCATCA-3'. I $\mathrm{B}$ was amplified using forward primer 5'-GGATACCTGGAGGATCAGATTA-3' and reverse primer
5'-CCACCTTAGGGAGTAGTAGATCAAT-3'. PCR amplification was performed with 32 cycles of $45 \mathrm{sec}$ denaturing at $94^{\circ} \mathrm{C}, 45 \mathrm{sec}$ annealing at $55^{\circ} \mathrm{C}$ and $10 \mathrm{~min}$ extension at $72^{\circ} \mathrm{C}$. A melting curve analysis was conducted to control for the specificity of the amplification products. The expression values were normalized by the $\beta$-actin expression. Moreover, the amplified gene fragments were separated in a $2 \%$ agarose gel and visualized by ethidium bromide staining and UV light.

Western blot analysis. Western blot analysis was performed as previously described at 24,48 and $72 \mathrm{~h}$ after the transfections. The antibodies included Rap1 monoclonal antibody (Santa Cruz Biotechnology, $60 \mathrm{kDa}$, mouse), $\beta$-actin monoclonal antibody (Abmart; $43 \mathrm{kDa}$, mouse), goat anti-rabbit and mouse IgG-HRP (Abmart). Cells were collected by trypsin digestion and washed twice with PBS. RIPA lysis buffer $(100 \mu$ l) (Soledad) was added. Then, protein was extracted, and protein concentrations were determined using BCA protein assay kit (Tiangen) based on the manufacturer's instructions. Protein samples $(30 \mu \mathrm{l})$ were loaded onto a NuPAGE 8\% TA gel (Invitrogen) and run at $80 \mathrm{~V}$. Next, the proteins were transferred to PVDF membranes (Millipore) using an iBlot Gel Transfer Device (Bio-Rad Mini Protein 3) at $200 \mathrm{~mA}$ for $1.5 \mathrm{~h}$. The membranes were blocked in $3 \%$ BSA blocking buffer for $2 \mathrm{~h}$, exposed to primary antibody overnight at $4^{\circ} \mathrm{C}$, and secondary antibody for $2 \mathrm{~h}$ at room temperature. After that, the membranes were washed with $1 \%$ PBST, and rinsed with Rap1 three times (5 min each time) and with $\beta$-actin three times ( 3 min each time). Excess reagent was removed. The membranes were covered with transparent plastic wraps. Images were acquired using darkroom development techniques.

In vivo studies. The animal protocol was approved by the the Institutional Animal Care and Use Committee of Kunming Medical University. Four-week-old BALB/c nude mice were obtained from Vital River Laboratories (Beijing, China) and maintained in a specific pathogen-free facility. These mice were randomly divided into four groups with 10 mice each group: i) control; ii) 5-FU treated; iii) Rap1 miRNA; and iv) Rap1 miRNA + 5-FU treated group. The mice were implanted subcutaneously into the right flank with Rap1 miRNA stable transfected and control HepG2 cells $\left(1.0 \times 10^{7}\right.$ cells in $0.2 \mu \mathrm{l}$ PBS per mouse). When palpable tumors developed (average volume $100 \mathrm{~mm}^{3}$ ), the mice in 5-FU treated and Rap1 miRNA +5 -FU treated groups were administered intraperitoneally with $5-\mathrm{FU}$ at a dose of $30 \mathrm{mg} / \mathrm{kg}$ every 3 days. Those in control and Rap1 miRNA groups were injected with the same volume of $0.9 \%$ saline. Tumor size was measured at 3-day intervals with a caliper (calculated volume $=$ shortest diameter ${ }^{2} \mathrm{x}$ longest diameter/2). Tumor growth was followed for 25 days from the first injection.

Immunohistochemistry for Rapl and caspase-3. At the termination of the experiments, the tumors were removed for histological examination. The tumor samples were fixed in $10 \%$ formaldehyde, embedded in paraffin and then cut into $3-\mu \mathrm{m}$ thick sections. Immunohistochemistry was conducted using streptavidin-peroxidase method with the EnVision Kit (Maixin Bio, Fuzhou, China). The sections were dewaxed 
in xylene and rehydrated in a graded series of ethanol. The tissue sections were treated by high temperature and pressure in $10 \mathrm{mmol} / \mathrm{l}$ sodium citrate $(\mathrm{pH} 6.0)$ for $2 \mathrm{~min}$ for antigen retrieval. Next, the primary anti-Rap1 antibody (1:100 dilution; Santa Cruz Biotechnology; $60 \mathrm{kDa}$ ) was added to the slides. The slides were incubated at $4^{\circ} \mathrm{C}$ overnight. After that, the slides were stained with secondary antibody, followed by incubation with diaminobenzidine kit for $10 \mathrm{~min}$, hematoxylin staining, vitrification with dimethylbenzene, and coverslip with mounting medium. The Rap1 and caspase- 3 expression were assessed at the center and the invasive front of the tumor in each section. A positive Rapl expression was defined as nuclear staining at both the cancer central and invasive front. A positive caspase-3 expression was defined as cytoplasmic staining.

Statistical analysis. Data are presented as the means \pm SD. Statistical analysis was performed using the SPSS version 14. The differences were evaluated by t-test. P-values $<0.05$ were considered to indicate a statistically significant result.

\section{Results}

Expression of Rapl in HCC cell lines. To determine the effect of Rap1 expression on the apoptosis in HCC cells, we first determined the expression of Rap1 in four HCC cell lines and normal liver cells by quantitative RT-PCR. Quantitative RT-PCR revealed that expression of Rap1 was significantly higher in HCC cell lines HuH-7, SMMC-7721, QGY-7703 and HepG2 as compared with normal liver HL-7702 cells. Given the relative high expression of Rap1 in HepG2 cells, this cell line was selected for subsequent experiments to determine whether inhibition of Rapl expression by miRNA would enhance cells apoptosis.

Effects of Rapl expression on apoptosis in HepG2 cells. To investigate the anti-apoptotic role of Rap1 in HCC cells, we knocked down the expression of Rap1 in HepG2 using RNA interference (RNAi) techniques with miRNA. Firstly, Rap1 protein levels were evaluated in transfected and control HepG2 cells by western blot analysis to test RNAi efficiency. The level of Rap1 expression in Rap1 miRNA-transfected cells was reduced significantly compared with those in empty plasmid transfected group, and control group at 24, 48 and $72 \mathrm{~h}$ after the transfections (Fig. 1). The results suggested that miRNA transfection led to specific suppression of Rap1 protein expression.

The anti-apoptotic effect of Rap1 in HepG2 cells was subsequently confirmed by TUNEL assay and flow cytometric analysis. The flow cytometric analysis revealed that of Rap1 knockdown cells had a significantly higher rate of apoptosis at 48 and $72 \mathrm{~h}$ after the transfection when compared with empty plasmid group and control group $(\mathrm{P}<0.05)$. At $48 \mathrm{~h}, 15.8 \pm 0.5 \%$ of adherent cells were apoptotic in Rap1 miRNA group, whereas $1.1 \pm 0.2 \%$ and $0.3 \pm 0.1 \%$ of adherent cells were apoptotic in empty plasmid group and control group, respectively. At $72 \mathrm{~h}$, Rap1 miRNA induced apoptosis in $\sim 33.0 \pm 2.3 \%$ of the cells, empty plasmid induced apoptosis in only $8.2 \pm 1.6 \%$ of the cells compared with $0.6 \pm 0.1 \%$ cell apoptosis in control group (Fig. 2). To gain further
$\mathbf{A}$

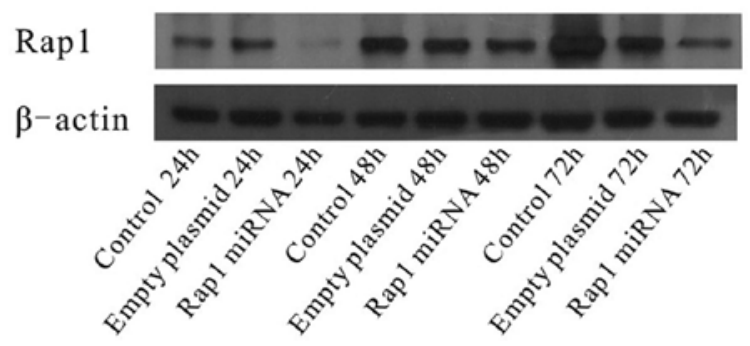

B

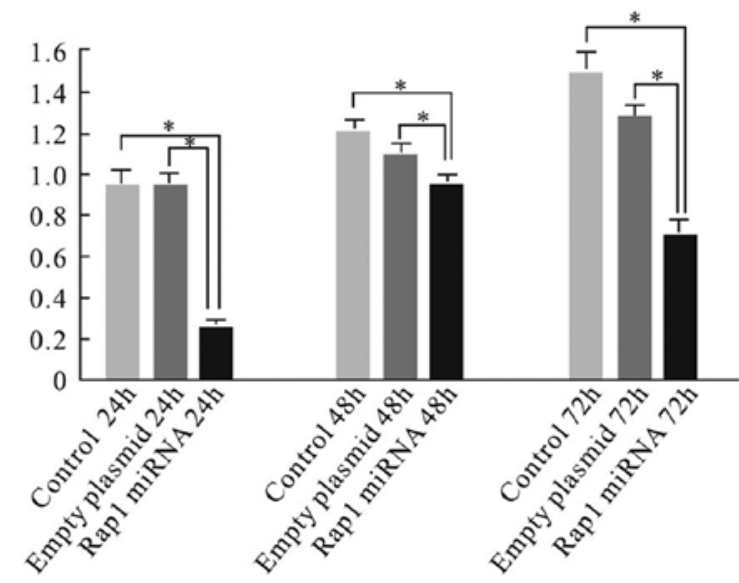

Figure 1. Western blot analysis of Rap1 expression in Rap1 miRNA transfected and control HepG2 cells, $\beta$-actin was used as a control $\left({ }^{*} \mathrm{P}<0.05\right)$.

information about the morphological changes, the cells from the three groups were evaluated of apoptosis with electron microscopy at $48 \mathrm{~h}$ after the transfection. Electron microscopy revealed that some shrinking cells with a ring of condensed chromatin at the interior surface of the nuclear envelope in Rap1 miRNA group (Fig. 3), which was consistent with the result of flow cytometric analysis. Take together, these results suggested Rap1 miRNA increased apoptosis in HepG2 cells.

Next, we investigated whether Rap1 miRNA would enhance chemosensitivity to 5-FU in HepG2 cells. HepG2 cells were treated with $0,0.1,0.2,0.3,0.4,0.5$ or $0.6 \mu \mathrm{M}$ 5 -FU for 24 at $48 \mathrm{~h}$ after the transfection. The cell viability was evaluated using the MTT assay. MTT assays revealed the Rap1 miRNA-transfected cells showed increased sensitivity to 5-FU as compared with the empty plasmid-transfected, and the control cells (Fig. 4).

Suppression of Rapl increases cell apoptosis through $N F-\kappa B$ signaling in HepG2 cells. We next investigated the mechanism responsible for the anti-apoptotic effect of Rap1 in HepG2 cells. We examined the expression of $N F-\kappa B$ p65 and $\mathrm{I} \kappa \mathrm{B}$ at mRNA level at $48 \mathrm{~h}$ after the transfection. Quantitative realtime RT-PCR analysis revealed that the NF- $\kappa$ B p 65 mRNA was downregulated significantly, whereas the I $\mathrm{B}$ mRNA was greatly upregulated in Rap1 miRNA-transfected cells compared with those in control cells $(\mathrm{P}<0.05)$ (Figs. 5 and 6), suggesting that $\mathrm{NF}-\kappa \mathrm{B}$ was suppressed in Rap1 miRNAtransfected HepG2 cells. These results indicate that Rap1 plays an anti-apoptotic role via the $\mathrm{NF}-\kappa \mathrm{B} / \mathrm{I} \kappa \mathrm{B}$ pathway. 
$48 \mathrm{~h}$

[B] FL3 Lin/FL1 Log

Control

Empty plasmid

[B] FL3 LIN/FL1 Log
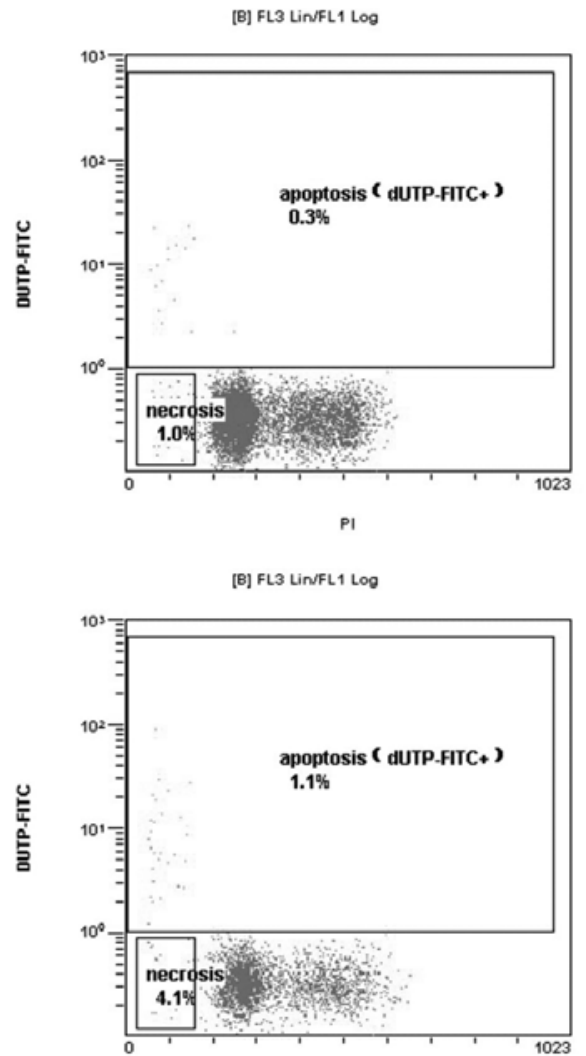

[B] FL3 Lin/FL1 Log

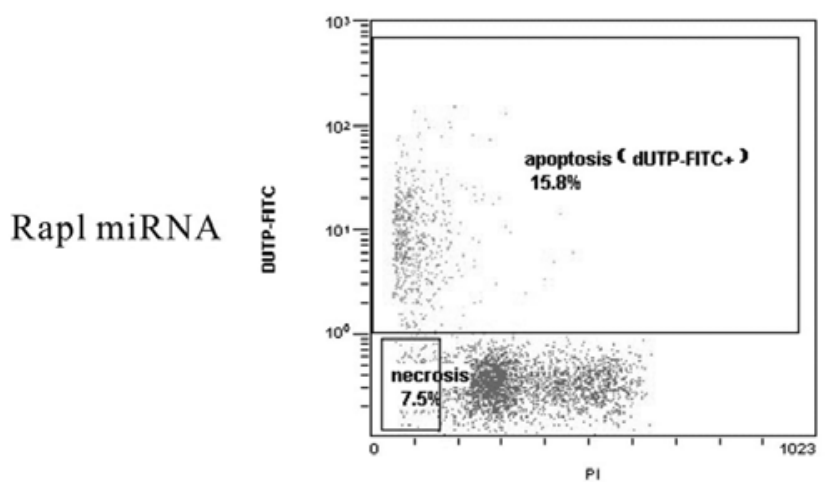

$72 \mathrm{~h}$

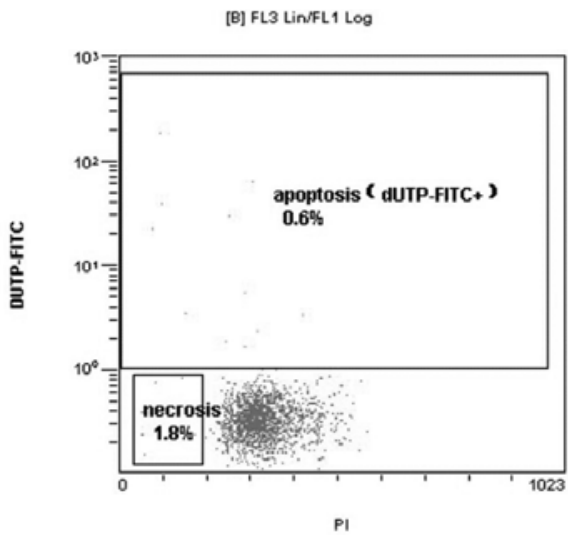

[B] FL3 Lin/FL 1 Log

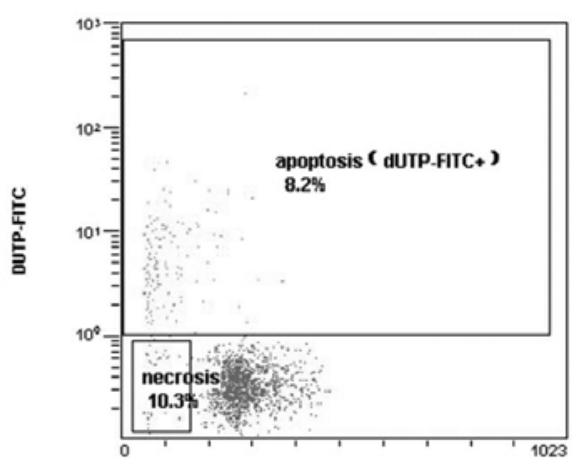

[B] FL3 Lin/FL 1 Log

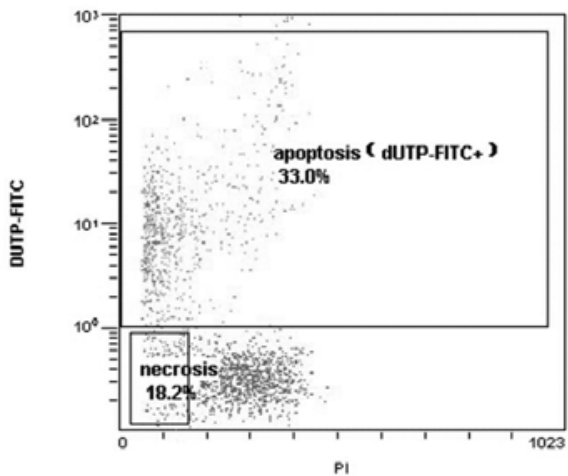

Figure 2. Flow cytometric analyses of the percentages of apoptotic cells at 48 and $72 \mathrm{~h}$ after the transfection.

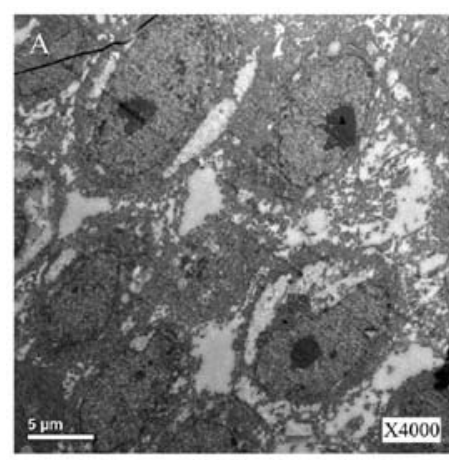

Control

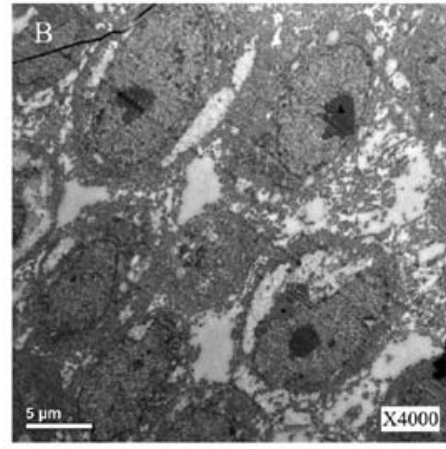

Empty plasmid

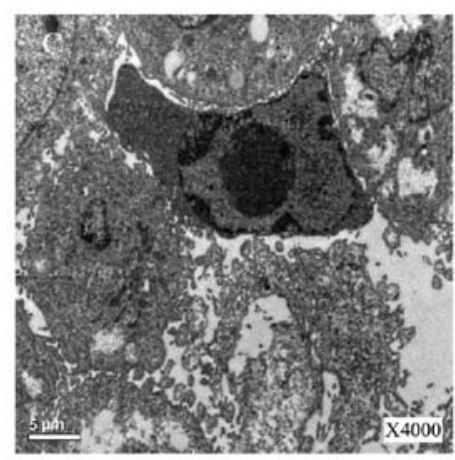

Rapl miRNA

Figure 3. Electron microscopy images (original magnification, x4000) of HepG2 cells. Cell shrinkage and chromatin condensation were noted in Rap1 miRNA group at $48 \mathrm{~h}$ after the transfection. 


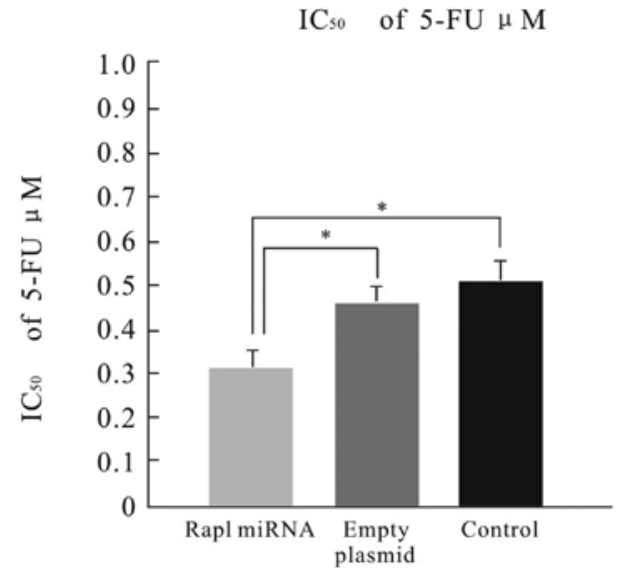

Figure 4. Growth inhibition by 5 -FU in HepG2 cells. HepG2 cells were plated on 96 -well plates and treated with $0,0.1,0.2,0.3,0.4,0.5$ or $0.6 \mu \mathrm{M}$ 5 -FU for $24 \mathrm{~h}$. Cell survival was determined using MTT assay. Each value represents the mean $\pm \mathrm{SD}$ from triplicate measurements. $\left({ }^{*} \mathrm{P}<0.05\right)$.

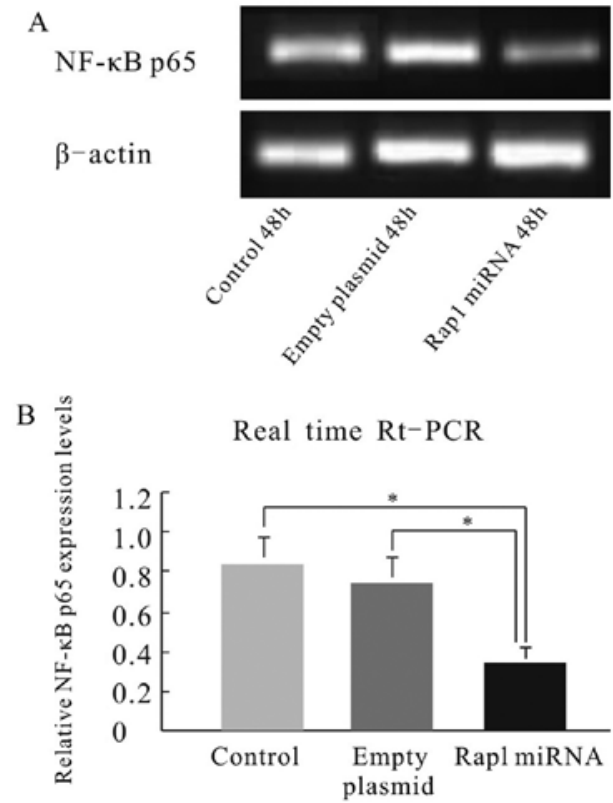

Figure 5. At $48 \mathrm{~h}$ after the transfection, the expression of NF- $\mathrm{kB}$ p 65 mRNA was determined with quantitative real-time RT-PCR analysis. The NF- $\mathrm{BB}$ p65 mRNA was downregulated significantly when compared with that in control cells $($ " $\mathrm{P}<0.05)$

Rap1 miRNA reduces HepG2 tumor growth in vivo. To determine the efficacy of Rap1 miRNA alone or combined with 5 -FU in vivo, we used a BALB/c murine xenograft tumor model with Rap1-deleted and control HepG2 cells. The size of the tumors was measured in three dimensions twice a week for 3 weeks, and the tumor volume was calculated. Mean tumor volume in Rap1-miRNA group was $851.2 \pm 32.6 \mathrm{~mm}^{3}$ compared to the average tumor volume of $1494.7 \pm 126.2 \mathrm{~mm}^{3}$ in control group at the termination of the experiment $(\mathrm{P}<0.05)$. Rap1 miRNA combined with 5-FU treatment led to a reduction of tumor growth even further as compared with 5-FU alone $\left(624.9 \pm 45.3 \mathrm{~mm}^{3}\right.$ vs. $\left.1424.0 \pm 108.6 \mathrm{~mm}^{3} ; \mathrm{P}<0.05\right)$ (Fig. 7). The results suggested that Rap1 miRNA inhibited liver cancer progression and enhanced sensitivity of $\mathrm{HepG} 2$ cells to 5-FU in vivo.

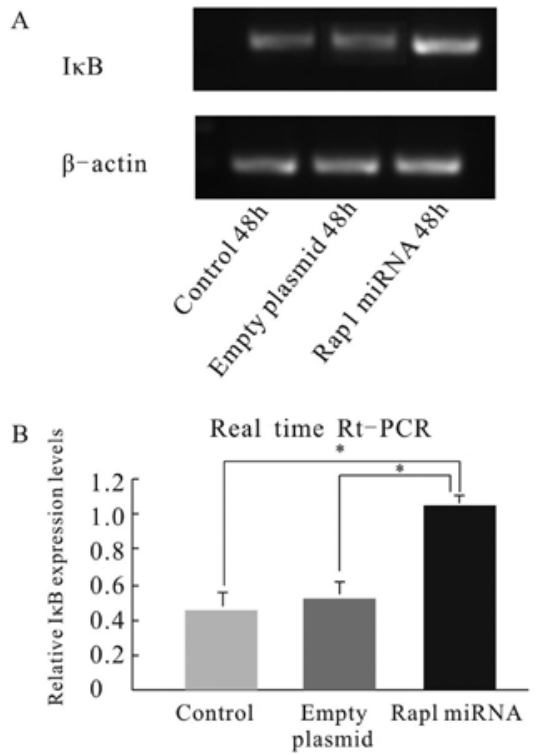

Figure 6. At $48 \mathrm{~h}$ after the transfection, the expression of $\mathrm{I} \kappa \mathrm{B}$ was determined with quantitative real-time RT-PCR analysis. The I $\mathrm{B}$ mRNA was upregulated significantly when compared with that in control cells $\left({ }^{*} \mathrm{P}<0.05\right)$.

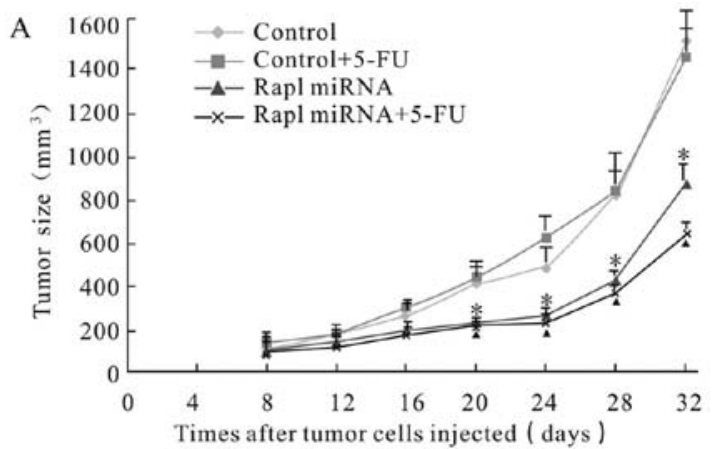

B

Control

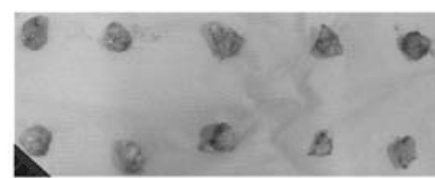

Control+5-FU
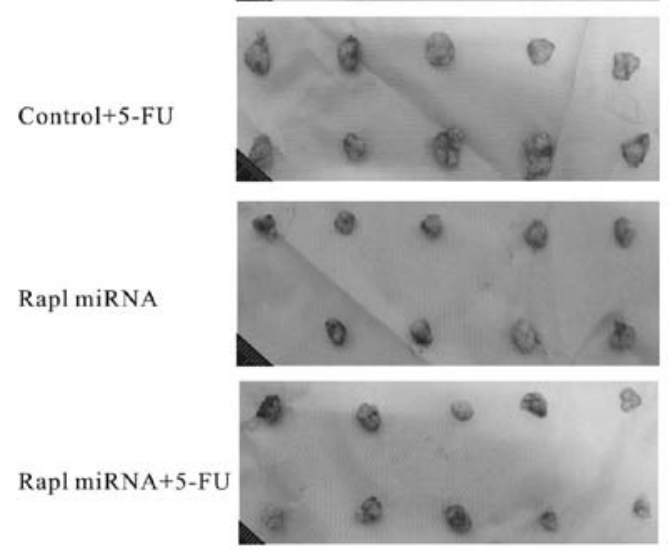

Figure 7. Effects of Rap1 miRNA and 5-FU on HepG2 tumor growth in nude mice. (A) Cohorts of 10 nude mice received subcutaneous injection with $1 \times 10^{7}$ Rap1 miRNA transfected or control HepG2 cells. On day 8 after the injection of tumor cells, the mice received intraperitoneal injection of 5-FU or the same volume of $0.9 \%$ saline twice a week, and tumor size was measured from day 8 to 32 . ${ }^{*} \mathrm{P}<0.05$ compared to the control; ${ }^{\wedge} \mathrm{P}<0.05$ compared to the control +5 -FU. (B) The tumors were removed from the mice in each group for immunostaining analysis at day 32 . 

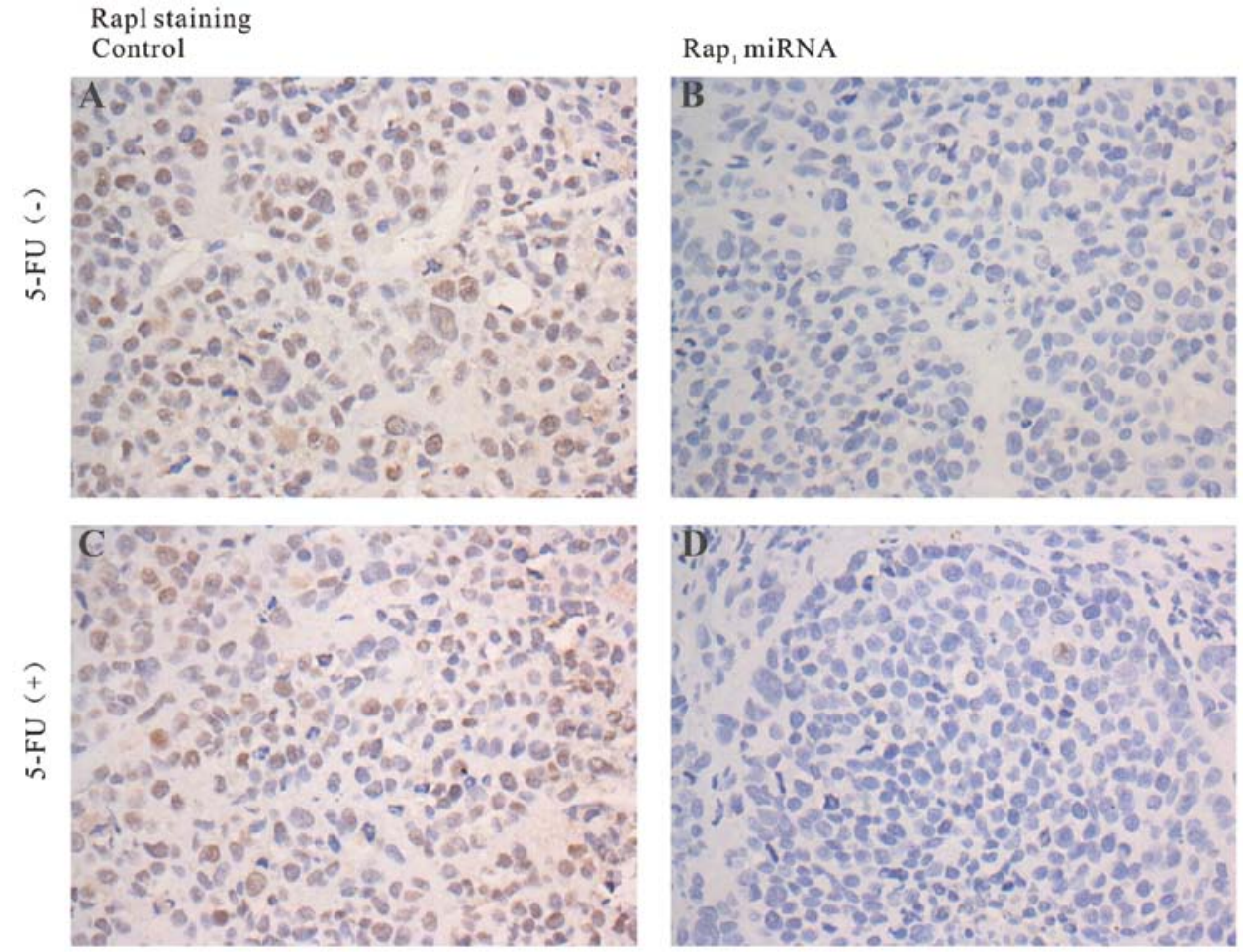

Figure 8. An immunohistochemical analysis of Rap1 in HepG2 tumors in vivo (original magnification, $\mathrm{x} 400$ ). Rap1 was undetectable in Rap1 knockdown tumors, whereas nuclear staining of Rap1 was observed in control tumors.
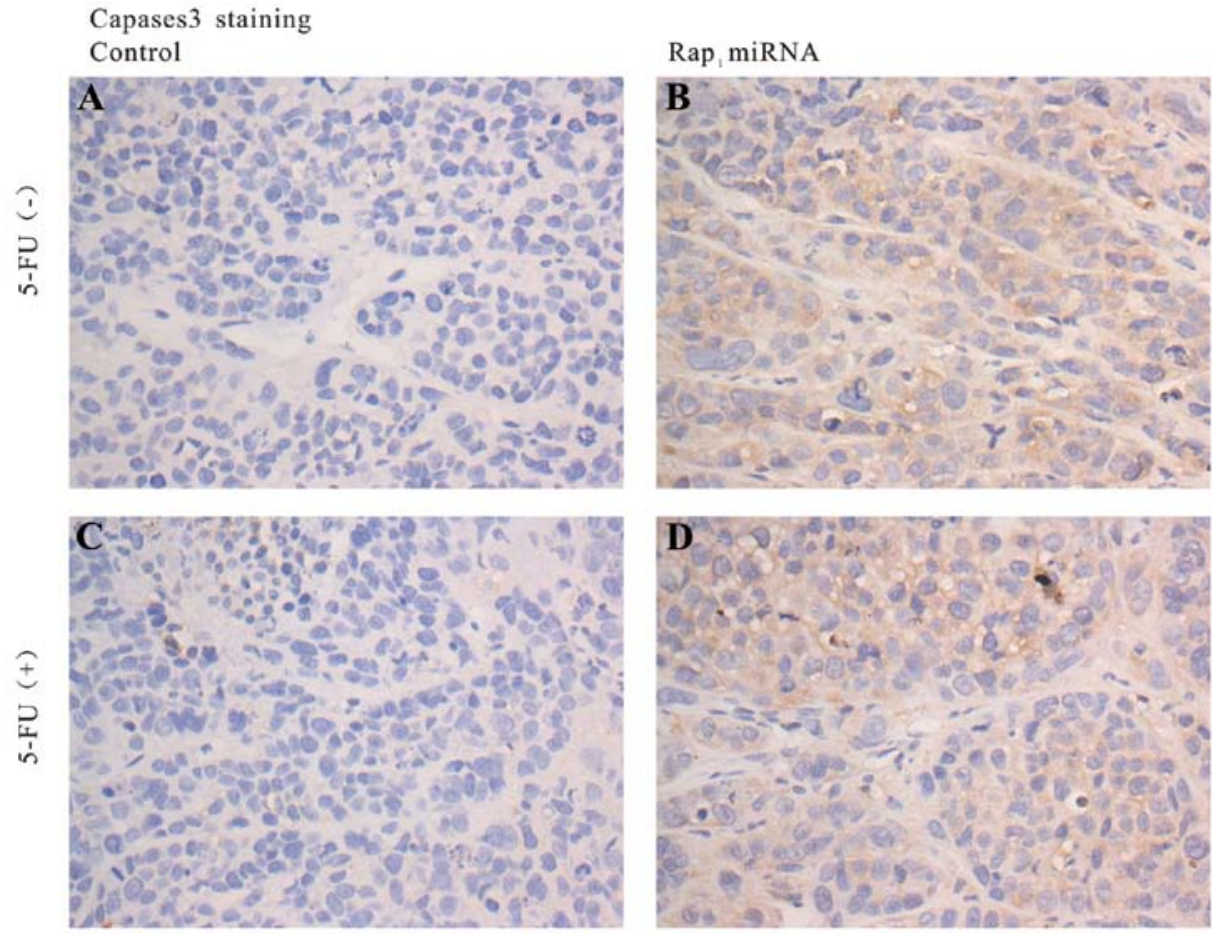

Figure 9. An immunohistochemical analysis of caspase-3 in HepG2 tumors in vivo (original magnification, $\mathrm{x} 400$ ). Cytoplasm staining of caspase-3 was detected in Rap1 knockdown tumors, whereas very little or no staining was detectable in control tumors.

We also investigated the expression of Rap1 and caspase-3 expression using immunohistochemical staining in harvested tumors. Immunohistochemical staining analyses revealed that Rap1 expression was significantly inhibited in Rap1 miRNA tumors, whereas Rap1 overexpression was observed in control tumors (Fig. 8). Caspase-3 expression was positive in Rap1 miRNA treated tumors, and negative in the controls (Fig. 9). The results demonstrated that knockdown of Rap1 dramatically enhanced caspase-mediated apoptosis in the mouse model of HCC. 


\section{Discussion}

Previous studies have demonstrated that arterial infusion chemotherapy improves the outcome of patients with advanced HCC (10,11). 5-FU regimen is widely used in arterial infusion chemotherapy for patients with advanced HCC (10). However, HCC is highly resistant to chemotherapy in some patients. Defect in apoptosis is a principal mechanism of drug resistance in HCC (5). Several studies have revealed that telomerase activity was associated with increased apoptotic and chemotherapeutic resistance in HCC (12-14). The expression of telomeric repeat-binding factor (TRF)1, TRF2 and TRF1 interacting protein 2 (TIN2) was found to correlate with the progression of hepatocarcinogenesis, and markedly upregulated from dysplastic nodules to $\operatorname{HCC}(15,16)$. As a member of telomere-binding proteins, Rap1 plays a role in maintaining telomere homeostasis and genomic integrity (17). In a recent study, Rap1 signaling was identified as a crucial factor in $\mathrm{TNF} \alpha$-induced apoptosis in breast cancers (9). However, the role of Rap1 on HCC progression and its underlying molecular mechanisms remain largely unknown. Therefore, in the present study, we examined the effect of knocking down Rap1 expression on apoptosis and 5-FU chemosensitivity in HCC cells, and analyzed its mechanisms.

Rap1 mRNA expression was initially assessed in 4 HCC cell lines using real-time PCR analysis. Rapl expression was detected in all the cell lines. Given the relative high expression of Rap1 in HepG2 cells, the cells were selected for Rap1 knockdown assay. Western blot analyses revealed that the expression of Rap1 was significantly suppressed in Rap1 knockdown HepG2 cells compared with those in the empty plasmid transfected, and control cells at 24, 48 and $72 \mathrm{~h}$ after transfection. In vivo, immunohistochemical analyses revealed that Rap1 expression in resected tumors was lower in the Rap1miRNA group than that in control group, which was consistent with the in vitro results. The results suggested miRNA interference was effective in knocking down the expression of Rap1 in vitro and in vivo.

Subsequently, the effects of Rap1 miRNA on apoptosis and 5-FU chemosensitivity were investigated in HepG2 cells. The flow cytometric analysis revealed that the cells in Rap1 knockdown group had a significantly higher rate of apoptosis at 48 and $72 \mathrm{~h}$ after the transfection compared with those in empty plasmid group and control group. The pro-apoptotic effect of Rap1 miRNA was further confirmed by electron microscopy. In vivo, caspase-3 expression in resected tumors was higher in the Rap1-miRNA group than in control group. The results demonstrated that knockdown of Rap1 was effective in inducing apoptosis in HepG2 cells.

Rap1 knockdown also resulted in a significant decrease in cell proliferation rate and an increase in 5-FU sensitivity in HepG2 cells. MTT assay showed that Rap1 miRNA cells showed increased sensitivity to $5-\mathrm{FU}\left(\mathrm{IC}_{50}=0.31 \mu \mathrm{M}\right)$ as compared with empty plasmid-transfected cells, or control cells. At the termination of the experiment in vivo, the mice in Rap1 miRNA transfected group had a significant reduction in tumor growth as compared with the control group. Rap1 miRNA combined with 5-FU treatment led to a reduction of tumor growth even further as compared with 5-FU alone. These results are in agreement with those reported by Teo et al (9) who found that knockdown of Rapl by siRNAs significantly sensitized MCF7 cells to TNF $\alpha$-induced and adriamycininduced apoptosis. Collectively, the findings suggest that increased Rap1 expression plays an anti-apoptotic role in HCC cells, inhibition of Rap1 with miRNA enhanced apoptosis and 5-FU sensitivity both in vitro and in vivo xenografts.

We found that knockdown of Rap1 resulted in increased $\mathrm{NF}-\kappa \mathrm{B}$ p 65 and decreased $\mathrm{I} \kappa \mathrm{B}$ mRNA levels in HepG 2 cell line. Similarly, Teo et al found that there was a positive correlation between high levels of cytoplasmic Rap1 and high levels of nuclear NF- $\kappa \mathrm{B}$ in breast cancer (9). NF- $\kappa \mathrm{B}$ is a transcription factor with five subunits: RelA (p65), RelB, $\mathrm{c}-\mathrm{Rel}, \mathrm{p} 50 / \mathrm{NF}-\kappa \mathrm{B} 1$, and $\mathrm{p} 52 / \mathrm{NF}-\kappa \mathrm{B} 2$. The heterodimeric complexe of p50/p65 (RelA) is predominantly detected in the cells. NF- $\kappa \mathrm{B}$ dimers are complexed with the inhibitory protein $\mathrm{I} \kappa \mathrm{B}$ and maintained in an inactive state in most cell types (18). Previous studies have demonstrated that $5-\mathrm{FU}$ induces apoptosis, and activate the $\mathrm{NF}-\kappa \mathrm{B}$ pathway in colon carcinoma and HCC models $(19,20)$. Activated NF- $\kappa \mathrm{B}$ pathway is known to play a vital role in apoptosis resistance in various malignancies including $\mathrm{HCC}$ through regulation of its downstream target genes $(18,21)$. Inhibiting $\mathrm{NF}-\kappa \mathrm{B}$ can increase 5-FU sensitivity in HCC (20). Some studies demonstrated $\mathrm{NF}-\kappa \mathrm{B}$ induced the expression of inhibitor of apoptosis protein-1 (c-IAP1) and c-IAP2. NF- $\kappa \mathrm{B}$ also upregulates the expression of Bcl-2 family (such as Bcl-2 and $\mathrm{Bcl}-\mathrm{xL}$ ), which plays a pivotal role in the inhibition of apoptosis $(8,21)$. It is likely that downstream gene targets of $\mathrm{NF}-\kappa \mathrm{B}$ are involved in Rap1-related apoptosis mechanism in HCC cells. Rap1 promotes cell survival through an NF- $\mathrm{B}-$ dependent pathway in HCC.

In summary, the present study revealed that the combined Rap1 inhibition and chemotherapy inhibited tumor development and induced higher apoptosis rates than chemotherapy alone and control group in HepG2 cells. Our data suggest that inhibition of Rap1 is a promising target of therapeutic approaches to render HCC cells more sensitive to apoptosis and chemotherapy. Targeting of Rapl via RNA interference is a potential therapeutic strategy.

\section{Acknowledgements}

The present study was supported by grants from the Applied Basic Research Programs of Science and Technology Commission Foundation of Yunnan Province (no. 2011FB064 and no. 2012FB065). The authors thank Dr Eduardo Briceño for reviewing the manuscript.

\section{References}

1. El-Serag HB and Rudolph KL: Hepatocellular carcinoma: epidemiology and molecular carcinogenesis. Gastroenterology 132: 2557-2576, 2007

2. Tang ZY, Ye SL, Liu YK, et al: A decade's studies on metastasis of hepatocellular carcinoma. J Cancer Res Clin Oncol 130: 187-196, 2004.

3. Padhya KT, Marrero JA and Singal AG: Recent advances in the treatment of hepatocellular carcinoma. Curr Opin Gastroenterol 29: 285-292, 2013.

4. Sankari SL, Masthan KM, Babu NA, et al: Apoptosis in cancer - an update. Asian Pac J Cancer Prev 13: 4873-4878, 2012.

5. Wu J, Hu D and Zhang R: Depletion of Bmi-1 enhances 5-fluorouracil-induced apoptosis and autophagy in hepatocellular carcinoma cells. Oncol Lett 4: 723-726, 2012. 
6. Wang $\mathrm{H}$ and Cho $\mathrm{CH}$ : Effect of $\mathrm{NF}-\kappa \mathrm{B}$ signaling on apoptosis in chronic inflammation-associated carcinogenesis. Curr Cancer Drug Targets 10: 593-599, 2010.

7. Gocho T, Uwagawa T, Furukawa K, et al: Combination chemotherapy of serine protease inhibitor nafamostat mesilate with oxaliplatin targeting NF- $\mathrm{KB}$ activation for pancreatic cancer. Cancer Lett 333: 89-95, 2013.

8. Monks NR, Biswas DK and Pardee AB: Blocking anti-apoptosis as a strategy for cancer chemotherapy: NF- $\mathrm{KB}$ as a target. J Cell Biochem 92: 646-650, 2004.

9. Teo H, Ghosh S, Luesch H, et al: Telomere-independent Rap1 is an IKK adaptor and regulates NF- $\mathrm{KB}$-dependent gene expression. Nat Cell Biol 12: 758-767, 2010.

10. Kaseb AO, Shindoh J, Patt YZ, et al: Modified cisplatin/interferon $\alpha-2 b /$ doxorubicin/5-fluorouracil (PIAF)chemotherapy in patients with no hepatitis or cirrhosis is associated with improved response rate, resectability, and survival of initially unresectable hepatocellular carcinoma. Cancer 119: 3334-3342, 2013.

11. Yamashita $\mathrm{T}$ : Current status of hepatocellular carcinoma treatment in Japan: hepatic arterial infusion chemotherapy. Clin Drug Investig 32 (Suppl 2): 15-23, 2012.

12. Spallarossa P, Altieri P, Aloi C, et al: Doxorubicin induces senescence or apoptosis in rat neonatal cardiomyocytes by regulating the expression levels of the telomere binding factors 1 and 2 . Am J Physiol Heart Circ Physiol 297: H2169-H2181, 2009.

13. Kato M, Nakayama M, Agata M, et al: Gene expression levels of human shelterin complex and shelterin-associated factors regulated by the topoisomerase II inhibitors doxorubicin and etoposide in human cultured cells. Tumour Biol 34: 723-733, 2013.
14. Biroccio A, Rizzo A, Elli R, et al: TRF2 inhibition triggers apoptosis and reduces tumourigenicity of human melanoma cells. Eur J Cancer 42: 1881-1888, 2006.

15. Oh BK, Jo Chae K, Park C, et al: Telomere shortening and telomerase reactivation in dysplastic nodules of human hepatocarcinogenesis. J Hepatol 39: 786-792, 2003.

16. Oh BK, Kim YJ, Park C, et al: Up-regulation of telomerebinding proteins, TRF1, TRF2, and TIN2 is related to telomere shortening during human multistep hepatocarcinogenesis. Am J Pathol 166: 73-80, 2005.

17. O'Connor MS, Safari A, Liu D, et al: The human Rap1 protein complex and modulation of telomere length. J Biol Chem 279: 28585-28591, 2004

18 Hayden MS and Ghosh S: Shared principles in NF- $\kappa B$ signaling. Cell 132: 344-362, 2008.

19. Körber MI, Klingenbrunner S, Bartsch R, et al: NF- $\kappa B$ addiction and resistance to 5 -fluorouracil in a multi-stage colon carcinoma model. Int J Clin Pharmacol Ther 51: 35-37, 2013.

20. Zhang H, Ozaki I, Hamajima H, et al: Vitamin K2 augments 5-fluorouracil-induced growth inhibition of human hepatocellular carcinoma cells by inhibiting NF- $\kappa \mathrm{B}$ activation. Oncol Rep 25: 159-166, 2011.

21. Cheng Q, Lee HH, Li Y, et al: Upregulation of Bcl-x and Bfl-1 as a potential mechanism of chemoresistance, which can be overcome by NF- $\kappa$ B inhibition. Oncogene 19: 4936-4940, 2000 . 